\title{
MATAR A TRIBO PARA FAZER NASCER A NAÇÃO: A (IN)VISIBILIZAÇÃO DA DIFERENÇA NA FORMAÇÃO DE PROFESSORES MOÇAMBICANOS
}

\author{
Matar a la tribu para dar a luz a la nación: la (in)visibilidad de la diferencia en la formación de \\ los maestros mozambiqueños
}

Kill the tribe to give birth to the nation: the (in)visibility of the difference in the training of mozambican teachers

Hermínio Ernesto Nhantumbo *

https://doi.org/10.38117/2675-181X.formov2020.v2i2n4.597-619

\section{RESUMO}

A análise problematiza a lógica essencialista articulada nos discursos que guiam a formação de professores em Moçambique baseada em políticas educacionais que procuram, a todo o tempo, invisibilizar a diferença. A utilização das línguas nativas e outras manifestações culturais nas políticas de formação de professores são rasuradas pela imposição arbitrária do português como língua oficial e exclusiva de ensino, o que gera contestações e exclusões. Sob o slogan matar a tribo para fazer nascer à nação, as várias manifestações culturais se constituíram ameaças aos projetos educacionais e nacionais, o que constitui um ponto de questionamento da perspectiva pós-colonial discutida por Homi Bhabha e apropriada por Elizabeth Macedo. Com esses autores olho para a cultura e currículo, como enunciação da diferença, fato que coloca em xeque às ópticas identitárias na formação de professores. Argumento, nesta óptica, que a formação de professores envolve o descarte de uma perspectiva da identidade.

PALAVRAS CHAVE: Formação de professores; cultura; currículo; hibridismo e diferença.

\section{RESUMEN}

El análisis problematiza la lógica esencialista articulada en los discursos que guían la formación de los maestros en Mozambique, basada en políticas educativas que buscan, en todo momento, hacer invisible la diferencia. El uso de los idiomas nativos y otras manifestaciones culturales en las políticas de formación de docentes se ve erosionado por la imposición arbitraria del portugués como idioma oficial y exclusivo de enseñanza, lo que genera impugnación y exclusión. Bajo la consigna 
de matar a la tribu para dar a luz a la nación, las diversas manifestaciones culturales han constituido amenazas para los proyectos educativos y nacionales, lo que constituye un punto de cuestionamiento desde la perspectiva postcolonial discutida por Homi Bhabha y de la que se apropió Elizabeth Macedo. Con estos autores, miro a la cultura y al currículum como una enunciación de la diferencia, un hecho que pone en jaque las perspectivas de identidad en la formación de los profesores. En esta perspectiva, sostengo que la formación de los profesores implica el descarte de una perspectiva de identidad.

PALABRAS CLAVE: Formación de profesores; Cultura; Plan de estudios; Hibridación y diferencia.

\section{ABSTRACT}

The analysis problematizes the essentialist logic articulated in the discourses that guide teacher education in Mozambique based on educational policies that seek, at all times, make the difference invisible. The use of native languages and other cultural manifestations in teacher education policies is eroded by the arbitrary imposition of Portuguese as the official and exclusive language of teaching, which generates contestation and exclusion. Under the slogan kill the tribe to give birth to the nation, local cultural manifestations have constituted threats to educational and national projects, which constitutes a point of questioning from the post-colonial perspective discussed by Homi Bhabha and appropriated by Elizabeth Macedo. With these authors, I look at culture and curriculum as an enunciation of difference, a fact that puts in check the identity perspectives in teacher education. In this perspective, I argue that teacher education involves discarding of an identity perspective.

KEYWORDS: Teacher education; Culture; Curriculum; Hybridity and difference.

\section{Contextualização teórica e conceitual: Cultura, currículo e diferença.}

Jacobs (2006, p. 9) faz uma contextualização interessante, aos referir que:

O recente crescimento na área da teoria curricular demonstra que as soluções para os problemas curriculares serão provavelmente mais eficazes quando lhes estiver subjacente um entendimento eclético de diferentes pontos de vista e perspectivas alternativas, do que se forem baseadas numa ideologia única. Os responsáveis pelo planeamento curricular, professores, políticos e outras pessoas envolvidas em questões curriculares estão constantemente a deliberar sobre a natureza do conhecimento desejável que entendem que os estudantes devem adquirir. 
MATAR A TRIBO PARA FAZER NASCER A NAÇÃO: A (in)visibilização da diferença na formação de professores moçambicanos

Um dos problemas que Moçambique ${ }^{1}$ tem-se debatido (talvez como herança do jugo colonial em que a ideia de europeização do indígena/nativo foi central em suas políticas educacionais e ideológicas), é a tendência de tentar fomentar, em suas políticas, únicas possibilidades de pensar o social. A ideia de construção da Nação como um projeto uno, homogêneo e hegemônico, atrelou outras questões como a padronização cultural, curricular e identidade nacional, como também a marginalização das línguas nacionais/nativas. O nacionalismo passou a constituir outra ideologia para fazer face ao colonialismo. Embora ambas vissem as tribos e as línguas nacionais/nativas como ameaças a serem combatidas, o modo como foram ressignificadas foi diferente.

É neste contexto que a teoria pós-colonial se mostra útil. Macedo e Lopes (2011, p. 208) entendem por teoria pós-colonial as perspectivas que "[...] lidam teoricamente com a resistência a todas as formas de globalismo e universalismo presentes nas manifestações contemporâneas [...] contrapondo-se à ideia de diálogo multi ou intercultural", olhando para a cultura como "fluxo e hibridismo". Por outro lado, "os estudos pós-coloniais, ao romper com as bases epistemológicas das ciências modernas, promovem a desconstrução dos essencialismos" e "colocam sob suspeita as imagens predefinidas que se desdobram de narrativas de unidade, mesmidade e homogeneidade" (OLIVEIRA; CAMÕES; FRANGELLA, 2019, p. 175) presentes nos projetos de nação, currículo de formação, padronização cultural e demais ideal. Segundo Bhabha (2019), esta teoria:

Intervêm naqueles discursos ideológicos da modernidade que tentam dar uma normalidade hegemônica ao desenvolvimento irregular e às histórias diferenciadas de nações, raças, comunidades e povos. Elas formulam suas revisões críticas em torno de questões de diferença cultural, autoridade social e discriminação política a fim de revelar os momentos antagônicos e ambivalentes no interior das racionalizações da modernidade (BHABHA, 2019, p. 275).

Neste contexto, a teoria pós-colonial proposta por Bhabha (2019) permite pensar o objeto da nossa análise (formação de professor articulada no projeto de construção da Nação; cultura, currículo e política curricular) não como algo coerente, homogêneo e

\footnotetext{
${ }^{1}$ De ponto de vista geográfico, Moçambique (com $801590 \mathrm{~km}^{2}$ de território) situa-se na costa oriental de África, banhado, a Este, pelo Oceano Índico e ladeado pelos seguintes países: Sudoeste - Suazilândia e África do Sul; Norte - Tanzânia; Noroeste - Zâmbia e Maláui; Oeste - Zimbábue. Segundo António Francisco (2010,p. 61) "o estabelecimento das fronteiras que configuram o território do país e a composição demográfica da população moçambicana" aconteceu "em 1891", anos seguintes à realização da Conferência de Berlim que decorreu em 1884-1885 na Alemanha, visando à partilha da África pelas potências imperialistas. Com a chegada dos portugueses em 1498 e a sua permanência até finais de 1974 e meados de 1975, Moçambique esteve sob o jugo colonial por cerca de 500 anos, tendo alcançado a independência em 1975.
} 
hegemônico, mas exatamente ao contrário, como fruto de escolhas arbitrárias, heterogêneas contingenciais e em contextos sempre a posteriori.

Face a esses rastros, questionamos: como a formação de professores se articulou com o projeto da morte da tribo para permitir a construção da nação? A que ponto o currículo de formação de professores foi constituído como um instrumento ao serviço da ideologia excludente? De que forma a enunciação torna o currículo de formação de professores em espaços de cultura e diferença, em que as tentativas de invisibilizar a diferença sofrem profundas ressignificações? Ver o currículo como uma fronteira cultural a partir do qual novas possibilidades emergem é um dos passos para ampliar os espaços de negociação. Negociação é a "estrutura de iteração que embasa os movimentos políticos que tentam articular elementos antagônicos e oposicionais sem a racionalidade redentora da superação dialética ou da transcendência" (BHABHA, 1998, p. 52). Dessa perspectiva, segundo Nhantumbo (2018, p. 187) citando Bhabha, (2012) emerge o hibridismo "como resultado dessas articulações/negociações que possibilitam a emergência de outros agenciamentos que desdobram outros fluxos culturais que passam a incorporar o fora do dentro; a parte no todo".

Contudo, nos parece oportuno situar outros conceitos preciosos para a presente análise. Stuart Hall (1997) dicotomiza o termo cultura em duas dimensões: substantiva e epistemológica. Segundo o autor, a dimensão substantiva se refere ao "lugar da cultura na estrutura empírica real e na organização das atividades, instituições, e relações culturais na sociedade, em qualquer momento histórico particular"; enquanto por dimensão epistemológica se entende "à posição da cultura em relação às questões de conhecimento e conceitualização, em como a "cultura" é usada para transformar nossa compreensão, explicação e modelos teóricos do mundo" (p. 16). Neste texto, entretanto, interessa-nos a dimensão epistemológica da cultura, não no modo em que o "epistemológico ainda está preso ao pressuposto do círculo hermenêutico cuja tendência é considerar a descrição da cultura em termos de uma totalidade, autônoma e autossuficiente", mas como "prática enunciativa, uma atividade de articulação humana que, por ser dialógica, tem condições de mapear os processos de desarticulações e realinhamentos que ocorrem no campo cultural" (SCHIMIDT, 2011, p. 23).

Neste âmbito, Homi Bhabha nos chama atenção para considerar que a cultura só “emerge como um problema, ou problemática, no ponto em que há uma perda de significados na contestação e articulação da vida cotidiana entre classes, gêneros, raças, nações" (BHABHA 2007, p. 63), que em muitas ocasiões produziram divisões binárias. Para este autor, a cultura é em si diferença. E tomar a cultura como diferença significa que "o ato de enunciação cultural - o lugar de enunciação - é atravessado pela différance da escrita" (p. 64), fato importante na/para a produção de sentidos abertos, em expansão. Por isso a cultura é uma construção ou "produção irregular e incompleta de sentido e 
MATAR A TRIBO PARA FAZER NASCER A NAÇÃO: A (in)visibilização da diferença na formação de professores moçambicanos

valor, frequentemente composta de demandas e práticas incomensuráveis, produzidas no ato da sobrevivência social" (BHABHA, 2019, p. 276).

A diferença cultural significada, também, como uma fronteira a partir do qual emergem novas possibilidades, tem sido expressa nos discursos identitários de diferentes matrizes políticas e curriculares, como um desafio a ser superado em nome de um projeto nacional (ideologia e identidade nacional) que tem favorecido mais a exclusão do que a união entre os moçambicanos. Uma expectativa de controle da diferença que Nhantumbo (2018, p. 187) citando Macedo (2015) explica a partir do reconhecimento de que "o imponderável $^{2}$, o simbólico, a zona fronteiriça ou de indecidibilidade ${ }^{3}$, a imprevisibilidade, a diferença $a^{4}$ são categorias semântico-epistemológicas que criam desconforto a todos os discursos essencialistas", desestabilizando "os seus fundamentos de modo a deixá-los vulneráveis para negociação".

Para Macedo (2015, p. 903-904) "há, no currículo, como em toda prática de significação, um desejo de controle, uma redução de uma infinidade de sentidos àqueles tornados possíveis pelos jogos de poder".

Contudo, para a presente abordagem a definição de Macedo (2003; 2006), segunda a qual o currículo é um espaço de enunciação cultural precisa ser muito bem explorada para a compreensão do (con)texto no qual estamos operando. Que significa dizer que o currículo (e, portanto, a cultura) são espaços de enunciação? Se apropriando das contribuições pós-coloniais para pensar o currículo, defendidas por Homi Bhabha, Elizabeth Macedo, explica que "tratar o currículo como enunciação pode ser um caminho para ir além dessa dicotomia" (2008, p. 93) que marcou as produções culturais e curriculares durante milênios, em que o social era visto numa lógica binária. Discutir questões ligadas ao currículo e à cultura é considerar, a princípio, que "a realidade é constituída pela linguagem" e que nem uma (a cultura), nem outro (o currículo) "podem ser tomados como espelho da realidade material", pois se enquadram em "sistemas simbólicos e linguísticos contingentes" (LOPES; MACEDO, 2011, p. 41). Este ponto parece importante porque a partir dele podemos compreender que o currículo e a cultura

\footnotetext{
${ }^{2}$ Segundo Elizabeth Macedo (2014, pp. 1550-1553) “o imponderável quer fazer referência ao imprevisível, mas também ao que não é digno de avaliação, sem deixar de considerar o sentido físico de algo que, como a luz, não tem peso". Nessa óptica, "o imponderável” é "aquilo que dá sentido à educação de qualidade. Uma educação que permite ao outro ser um outro singular, ou, nas palavras de Derrida (2008), aquilo que não foi inventado".

${ }^{3}$ Nas palavras de Derrida, citado por Gabriel (2017, p. 523) "os indecidíveis são unidades de simulacro, falsas propriedades verbais, nominais ou semânticas que não se deixam mais compreender na oposição filosófica (binária) e que, entretanto, habitam-na, opõem-lhe resistência, desorganizaram-na, mas sem nunca constituírem um terceiro termo, sem nunca dar lugar a uma solução na forma da dialética especulativa (DUQUE-ESTRADA, 2002, p. 13).
}

${ }^{4}$ Enquanto algo inesperado sobre o qual nunca pensamos. 
fazem parte de sistemas simbólicos e por isso passiveis de ser enunciados, permitindo a manifestação da subjetividade/identificação.

Importa considerar que entender o currículo como "uma prática discursiva [prática de significação] de atribuição de sentidos" (LOPES; MACEDO, 2011, p. 41-42) não significa de modo algum fechar os seus sentidos/significados, mas apenas, pontos de partida para compreendermos a ideia defendida por Macedo de entender o "currículo como cultura" e "cultura como diferença" (OLIVEIRA; FRANGELLA, 2017, p. 88). ${ }^{5}$ Para Macedo o currículo é:

Prática de atribuição de sentidos que se dá a partir de alguns sentidos partilhados. Ele será sempre híbrido, envolvendo significados novos e velhos que habitam o interstício entre certo sentido original, historicamente construído, e aquele que se constrói ininterruptamente (MACEDO, 2008, p. 93).

Essa ideia de Macedo se inspira nas reflexões de Bhabha (1998, p. 27) segunda a qual:

O trabalho fronteiriço da cultura exige um encontro com "o novo" que não seja parte do continuum de passado e presente. Ele cria uma ideia do novo como ato insurgente de tradução cultural. Essa arte não apenas retoma o passado como causa social ou precedente estético, ela renova o passado, refigurando-o como um "entre-lugar" contingente, que inova e interrompe a atuação do presente. $\mathrm{O}$ "passado-presente" torna-se parte da necessidade, e não da nostalgia, de viver.

O currículo como esse lugar de fronteira ou intersticial possibilita que as perspectivas prescritivas sejam contestadas em favor da diferença ${ }^{6}$, entendida como:

Processo da enunciação [...] [e] de significação através do qual afirmações da cultura ou sabre a cultura diferenciam, discriminam e autorizam a produção de campos de força, referência, aplicabilidade e capacidade (BHABHA, 1998, p. 63).

Compreendo que os sentidos que se criam no currículo como um espaço de enunciação são/estão sempre em processos contínuos de (res)significação. Na discussão sobre a cultura está, de forma íntima, a noção de diferença cultural que torna a enunciação da cultura "conhecível, legitimo, adequado à construção de sistemas de identificação cultural” (BHABHA, 2007, p. 63). Argumento que o currículo é parte desse sistema de

\footnotetext{
${ }^{5}$ In LOPES e Oliveira, 2017, p. 88.

${ }^{6}$ A partir dessa constatação fica demarcada a distinção entre diversidade (como objeto epistemológico por ser entendido como "reconhecimento de conteúdos e costumes culturais pré-dados" ou definidos a priori) e diferença cultural (como processo de significação/enunciação numa lógica a posteriori) (BHSBHA, 2007; p. 69).
} 
MATAR A TRIBO PARA FAZER NASCER A NAÇÃO: A (in)visibilização da diferença na formação de professores moçambicanos

identificação cultural na medida em que ele (re)produz, também, a diferença. Macedo (2006, p. 105) vê o "currículo [...] como uma prática cultural que envolve, ela mesma, a negociação de posições ambivalentes de controle e resistência". Para a autora, "o cultural não pode [...] ser visto como fonte de conflito entre diversas culturas, mas como práticas discriminatórias em que a diferença é produzida". A enunciação é muito importante nesses processos todos. Bhabha (2007) explica, que:

O processo enunciativo introduz uma quebra no presente performativo da identificação cultural, uma quebra entre a exigência culturalista tradicional de um modelo, uma tradição, uma comunidade, um sistema estável de referência, e negação necessária da certeza na articulação de novas exigências, significados e estratégias culturais no presente político como prática de dominação ou resistência (BHABHA, 2007, p. $64)$.

Neste âmbito, as prescrições no currículo são ressignificadas de uma perspectiva a priori para a posteriori, e uma das condições para a enunciação é o Terceiro-espaço. $\mathrm{O}$ Terceiro-espaço tem o papel de possibilitar "que o significado e os símbolos da cultura não tenham unidade ou fixidez primordial e que até os mesmos signos possam ser apropriados, traduzidos, re-historicizados e lidos de outro modo" (1998, p. 68). Esta questão nos leva a interrogar, que implicações têm tal posicionamento no ato de pensar o currículo? O Terceiro-espaço possibilita que o currículo se transforma em um espaço por excelência de negociação, onde o consenso não significa o fim dos conflitos ou de momentos antagônicos, mas a fronteira a partir do qual emergem novas possibilidades, de formar novos sujeitos/professores, já despidos da antiga concepção moderna de homem ${ }^{7}$.

Pelo fato do espaço de enunciação ser ambivalente, o Terceiro-espaço permite questionar "as reivindicações hierárquicas de originalidade ou "pureza" inerentes às culturas", mostrando que tais intenções "são insustentáveis", pois não escapam aos processos de "hibridismo" (BHABHA, 2007, p. 67). O hibridismo, no entanto, tem tido um papel muito importante. Alice Lopes (2006, p. 40) explica que "o hibrido não resolve as tensões e contradições entre os múltiplos textos e discursos, mas produz ambiguidades, zonas de escape de sentidos", onde "a resistência e dominação não ocupam posições fixas", mas sim precárias [(marcas da impossibilidade de transparência da língua), provisórias (ainda que tenha duração de décadas) e contingentes (nada que lhe seja intrínseco garante sua necessidade) (Cf. LOPES; OLIVEIRA, 2017, p. 25)]. Esta posição

\footnotetext{
7 A modernidade concebeu os sujeitos/homens como “[...] centrado, da razão universal, da consciência unitária e homogênea" mas que de acordo com as perspectivas pós-estruturais, tal homem morreu e deu "lugar a um sujeito descentrado, fragmentado e contraditório," (SILVA, 2001 e 2007) citado por (FERREIRA e SANTOS, 2017, p. 60) sendo entendido como constituído na e pela linguagem.
} 
de Alice Lopes concorda com a de Elizabeth Macedo, segundo a qual "hibridizar significa renunciar à ideia de identidade baseada em raízes de qualquer natureza” (2006, p. 107).

Por isso Macedo (2006, p. 105), refere que o próprio "currículo é ele mesmo um híbrido, em que as culturas negociam com-a-diferença”, (considerando que para a sua composição não se pode selecionar as culturas por não terem existência prévia, mas resultado de processos de "fluxos culturais $\left.{ }^{8}\right)$ ". Por isso que quando falo de currículo, no geral, neste domínio, entenda-se que me refiro a sua componente intrinsecamente híbrido. Falar de cultura ou currículo hibrido quer dizer em outras palavras que os fundamentos/essências/estruturas são o tempo todo abalados pela produção de novos sentidos e significados de modo que não podem se cristalizar (LOPES; MACEDO, 2011, p. 213-214), por estarem incessantemente a ser mediado pela linguagem. Dizer que o social (ou tudo o que pode ser nomeado pela linguagem) é mediado pela linguagem, possibilita compreender que nenhum discurso pode se sedimentar, pois o caráter provisório, contingente e precário da linguagem impossibilita a sutura dos sentidos em disputa.

A indeterminação da linguagem está associada ao signo, que como sabemos, "não coincide com a coisa ou conceito", pois ele "não é uma presença, ou seja, a coisa ou o conceito não estão presentes no signo" (SILVA, 2000, p. 78). Por outro lado, na sua apropriação, Macedo (2006, p. 106) explica que tomar o currículo como enunciação é considerar "um espaço-tempo de interação entre culturas" que permite "[...] estar na fronteira $[\ldots]$ no limiar entre as culturas, [...] em que o hibridismo é a marca e em que não há significados puros". Por isso "a enunciação está sempre aberta à alteridade, obrigando à negociação constante com essa alteridade (que nos constitui)" (MACEDO, 2017, p. 551) e nos faz existir/dialogar como sujeitos e "objetos" de enunciação.

Considerar, pois, a lógica do currículo como uma enunciação cultural significa rechaçar todas as tentativas de concepção de sujeitos modernos/professores, (uno, centrado, homogêneos), equivalente a uma imagem/estereotipo que se quer que todo o mundo se aproprie e se iguale. Significa adiar perpetuamente a concepção de um sujeito reprodutor, imitador e sem criatividade e autonomia, sobretudo quando desempenha o papel de docente/discente. Significa colocar a objetividade defendida pelas metanarrativas em xeque em favor de processos contínuos de subjetividades/ subjetivação. Questões antes generalizáveis são, através da enunciação, contestadas e vistas na sua especificidade, na sua singularidade graças ao papel de se pensar o currículo como uma enunciação cultural. Nas palavras de Macedo, enunciação cultural

\footnotetext{
${ }^{8}$ Segundo Macedo (2006, p. 106), "para Bhabha (2003), a noção de cultura deve ser tomada numa perspectiva interativa como algo constantemente recomposto a partir de uma ampla variedade de fontes num processo híbrido e fluido". É também nessa perspectiva que julgo ser produtivo pensar o currículo.
} 
MATAR A TRIBO PARA FAZER NASCER A NAÇÃO: A (in)visibilização da diferença na formação de professores moçambicanos

permite/possibilita "pensar o currículo para além da prescrição" (questões/processos definidas a priori), o que implica lidar com a emergência inesperada da diferença (questões/processos a posteriori).

Nesta perspectiva, como prática discursiva, “o currículo constrói a realidade, nos governa, constrange nosso comportamento, projeta nossa identidade, tudo isso produzindo sentidos" (LOPES; MACEDO, 2011, p. 41) ou "efeitos políticos (materialidades) para o que seja educar, política, formação, qualidade etc.”. (ALMEIDA; CUNHA, 2017, p. 151).

Por outro lado, a ideia de tomar o currículo como uma enunciação cultural questionou/questiona as várias formas de pensar o currículo desde a década de $60^{9}$ (currículo em ação; nulo; formal, oculto, etc.), construindo nova lógica de ver o poder (de universal e central para singular e pluri-versal com menor hierarquia e verticalidade possível devido aos espaços de negociação sempre criados). Neste contexto, enunciar significa hibridizar e sendo o "currículo um espaço hibrido de negociação", ele será sempre um lugar de enunciação cultural e de diferença que buscará as (res)significações do social. Operar o currículo assumindo-o como hibrido é inaugurar "[...] um espaço de negociação, onde o poder é desigual, mas a sua articulação pode ser questionável" (BHABHA, 2012) e perturbada. Nestes termos, constituir um currículo único que procura/com pretensão de/dar conta de todas as demandas sociais "de uma vez por todas", não encontra cabimento nesta óptica trazida por Macedo.

Pensar o currículo como processo de enunciação cultural possibilita questionar toda à pretensão/tentativas de se reestabelecer às verdades criadas pelas metanarrativas de que existem culturas universais e locais e abrir espaço para a compreensão de que existem, sim, culturas parciais, tal qual advoga Bhabha. Neste processo, as hegemonias são severamente combatidas, através de um processo de desconstrução dos seus fundamentos, abrindo espaço para novas (res)significações. Nesta perspectiva, por exemplo, a ideia de currículo único (de formação de professores) é problemática porque ela procura borrar o antagonismo/espaços de negociações tão importantes aos processos de identificação/subjetivação. Um dos propósitos do currículo único, segundo seus defensores, é impor uma "solução" visando acabar com "injustiças" sociais causadas pela suposta "má" qualidade educação. Tem também a pretensão de consolidar a ideia de identidade nacional, forjando ideais homogêneos e padronizados, fato que é problematizado por Homi Bhabha. Segundo esse autor (1998, p. 24) a ideia de uma “[...] identidade nacional pura só pode ser atingida a partir da morte literal e figurativa dos

\footnotetext{
${ }^{9}$ Segundo Macedo (2006, p. 101), existiu várias propostas de currículos: "pré-ativo e interativo (JACKSON, 1968); como fato e como prática (YOUNG; WHITTY, 1977); oficial, percebido, operacional e experiencial (GOODLAD, 1979); prescrito, apresentado, moldado, em ação e realizado (Gimeno Sacristán, 1988); pré-ativo e ativo (GOODSON, 1995).
} 
complexos entrelaçamentos da história e por meio das fronteiras culturalmente contingentes da nacionalidade moderna". Daí a própria ideia de nação se inscreve como enunciação ou narração. Argumento que tais discursos expressam promessas que jamais serão cumpridas. Na medida em que tais promessas envolta do discurso de currículo único:

[...] vêm restringindo os sentidos de educação àquilo que pode ser por elas "trocado". Elas vêm expulsando da educação toda diferença e toda singularidade que não são, por natureza, antecipáveis e sem as quais educação, justiça e democracia não fazem sentido. Porque educação, justiça e democracia requerem alteridade para serem vividas como tal (MACEDO, 2016, p. 63).

O apelo à alteridade/diferença como algo não antecipável se configura como um dos caminhos possíveis para se pensar o currículo não como único, mas como um devir/diferir. Daí que as lógicas definidas a priori perdem os seus sentidos em favor dos processos a posteriori. "Esses fluxos estão atravessados por relações de poder diversas e complexas que viabilizam a hibridização e não podem ser fixadas de forma absoluta" (OLIVEIRA; CAMÕES e FRANGELA, 2019, p. 174) como se pretende fazer com a ideia de um currículo único; de nação e de formação de professores para servirem interesses nacionalistas.

Não negamos o papel importante que o Estado presta aos processos formativos, muito menos menosprezamos as relações de poder aí existentes até porque essa tarefa não cabe a nós como pesquisadores realizar, mas insistimos em pensar as políticas curriculares e o currículo "em termos de negociação, articulação, produções hibridas e contingentes” (OLIVEIRA; CAMÕES; FRANGELA, 2019, p. 173). Que leituras se podem extrair do discurso envolto das políticas curriculares de formação de professores em Moçambique? Para isso o ponto a seguir nos pode dar uma luz.

\section{A tribo deve ser morta: formação de professores no contexto da construção da nação}

A independência de Moçambique face ao colonialismo português foi alcançada em 25 de junho de 1975, fruto de enfrentamento militar entre a Frente de Libertação de Moçambique (FRELIMO) e o regime colonial, guerra que durou 10 anos, pois decorreu de 1964 até 1974. Durante o conflito, a FRELIMO criava nas zonas em que libertava, um tipo específico de educação, desta vez revestida dos ideais, não colônias, mas nacionalistas. Como o enfrentamento militar iniciou do norte ao sul do país, assim começou o alastramento do processo educacional nacionalista. Neste contexto, "as zonas libertadas são consideradas", segundo Gonçalves (2015, p. 118), "na literatura oficial, como berço da educação Moçambicana", pois foi lá em que o movimento nacionalista ganhou, pela primeira vez, um espaço em que podiam administrar Moçambique depois 
MATAR A TRIBO PARA FAZER NASCER A NAÇÃO: A (in)visibilização da diferença na formação de professores moçambicanos

de longos anos de jugo colonial. Na verdade, a independência nacional significou um momento de transição de uma ideologia colonial para uma nacionalista, onde as especificidades culturais e linguísticas continuaram a serem rasuras.

O nacionalismo como uma ideologia procurou criar "pureza" nos moçambicanos através do ensino que pudesse forjar identidade nacional, o que é questionado, na medida em que não existem culturas ou etnias puras, mas hibridismos.

Contudo, com a nacionalização do ensino em 1975 "a qualidade de ensino que o novo governo poderia dar, era" segundo Ngoenha (2000, p. 77) "certamente inferior ao ensino dispensado pelo sistema colonial português e pelos diferentes autores privados, como as igrejas protestantes e outros". Essa qualidade decresceu, em parte, devido à fuga de quadros portugueses (e de alguns moçambicanos formados que decidiram servir a Portugal); a falta de um Sistema Nacional de Educação (SNE) e de seus derivados (Planos curriculares/currículo; Política de Educação, estratégias e etc.), crise financeira, instabilidade político-social, o que deixou o país numa situação caótica, agudizado por uma taxa elevadíssima de analfabetismo que "rondava os 94\%" (GASPERINI, 1989, p. 12).

Por outro lado, o mosaico sociolinguístico (24 grupos linguísticos ${ }^{10}$ ) que caracteriza o país levou à opção política pelo Português como língua de unidade nacional, capaz de garantir um sistema educativo que unisse os moçambicanos ${ }^{11}$. Uma opção que gera conflitos e questionamentos de vários grupos que se colocam contra a secundarização das línguas nacionais, num contexto em que a 'descolonização das mentes' (THIONG'O, 1986) é fator político importante para a afirmação do projeto nacionalista de nação. A imposição dessa posição política pelos governantes parece operar numa perspectiva binaria em que na escolha de um ou do outro não há possibilidades de uma terceira, quarta, quinta etc. via.

Nesse contexto analisamos o que está em jogo na afirmação de uma orientação política em que "matar a tribo para construir a nação" (MACHEL, 1974) se constituí uma bandeira importante nos primeiros anos de Moçambique independente e é

\footnotetext{
${ }^{10} \mathrm{~A}$ imprecisão de dados/informações sobre quantas línguas nacionais/grupos etnolinguísticos existem no país não permite enunciarmos com certeza. Armindo Ngunga (2012), por exemplo, identifica 41 línguas, enquanto Zimbico (2017) identifica 32 línguas. Marcelino Liphola, citado por Cabaço (2007, p. 20) refere que "dentro das fronteiras que delimitam a atual República de Moçambique, estão hoje identificados [...] vinte e quatro grupos linguísticos".

${ }^{11}$ Segundo o Ministério da Educação (MINED) e Instituto Nacional de Desenvolvimento de Educação (INDE), "dados do $1^{\circ}$ censo geral da população de 1980 apontam para cerca de $1,2 \%$ da população moçambicana que tem a língua oficial (Português) como materna, 24\% que a fala como língua segunda e, cerca de 75\% que não a fala (apenas fala as Línguas Locais/Maternas) " (INDE/MINED, 2003, p. 12).
} 
ressignificada até aos dias de hoje. É tendo em vista o desafio de construir um projeto de nação moçambicana, sem perder de vista a pluralidades de sentidos em disputa nas tentativas de significar um sujeito moçambicano (através da formação de professores) que para se constituir como tal precisa abdicar de seus pertencimentos locais, sua tribo, inclusive a sua língua materna, que essa analise se organiza buscando problematizar os limites impostos nas tentativas de unificação/padronização cultural.

Visando fazer face aos problemas acima narrados, foi necessário, primeiro, criar, em 1975, uma estrutura educacional ligada ao novo governo, denominado Ministério de Educação e Cultura (MEC); segundo, criar o SNE. É nesse cenário que em 1981 o MEC apresentou a primeira proposta do SNE, denominada Linhas Gerais do Sistema Nacional de Educação, somente aprovada em 1983 (Lei no .04 de 23 de março de 1983) e que tinha como principal objetivo "formar o Homem Novo livre do obscurantismo, da superstição e da mentalidade burguesa e colonial, um homem que assume os valores da sociedade socialista” (MOÇAMBIQUE, 1983, p. 113). Segundo Gasperini (1989, p. 32):

Os primeiros sete anos de independência foram caracterizados por uma reforma destinada a realizar algumas mudanças no sistema herdado, para evitar o colapso da única estrutura de formação de que o país dispunha de, e por uma tentativa de resolver a curto prazo a falta de quadros.

Contudo, de 1975 até a aprovação do SNE em 1983, o processo de ensino foi dirigido pelo MEC que usou, não só, as experiências educacionais da FRELIMO nas "zonas libertadas", como também eram usadas conteúdos "numa estrutura velha, o que por vezes sufocava o seu carácter inovativo" (GASPERINI, 1989, p. 32). Neste âmbito, o SNE foi estruturado comportando cinco subsistemas, nomeadamente: Subsistema de Educação Geral; Subsistema de Educação de Adultos; Subsistema de Educação TécnicoProfissional; Subsistema de Formação de Professores e Subsistema de Educação Superior. Para a presente análise, nos interessa o Subsistema de Formação de Professores, sobretudo os discursos ${ }^{12}$ que norteiam e articulam o seu currículo. Para esta análise consideraremos três momentos do SNE, que coincidentemente correspondem às três leis que estabeleceram o sistema, nomeadamente: Lei $n^{\circ}$ 04/1983 de 23 de Março; Lei $n^{\circ}$ 06/1992 de 6 de Maio; e Lei $n^{\circ}$ 18/2018 de 28 de Dezembro. Um aspecto importante a realçar que perpassam as três leis do SNE é que "os curricula e programas de ensino

\footnotetext{
12 Hall (1997, p. 29) explica que discurso é “uma série de afirmações, em qualquer domínio, que fornece uma linguagem para se puder falar sobre um assunto e uma forma de produzir um tipo particular de conhecimento. O termo refere-se tanto à produção de conhecimento através da linguagem e da representação, quanto ao modo como o conhecimento é institucionalizado, modelando práticas sociais e pondo novas práticas em funcionamento.
} 
MATAR A TRIBO PARA FAZER NASCER A NAÇÃO: A (in)visibilização da diferença na formação de professores moçambicanos

escolar, com exceção do ensino superior, têm o carácter nacional e são aprovados pelo Ministro que superintende a área de educação" (MOÇAMBIQUE, 2018, p. 24).

\title{
Políticas de formação de professores em Moçambique
}

Em 1970, cinco anos antes da independência nacional enquanto decorria o enfrentamento militar entre colonizador e colonizado, Samora Machel, presidente da FRELIMO - mais tarde Presidente da República (1975-1986) - fez um discurso que norteou a vida do país, em particular o Sistema Nacional de Educação (SNE) aprovado pelas Leis: 4 de 23 de Março de 1983; e a n 6 de 6 de Maio 1992. Tal discurso se resumiu no slogan "morra a tribo para que nasça a Nação" (MAZULA, 1995, p. 105). Cinco anos depois da independência nacional, o discurso foi ressignificado para "nós matamos a tribo para fazer nascer à nação ${ }^{13}$ " (LIMA, 2016, p. 19), como se a tribo tivesse sido, de fato, exterminada nos moçambicanos. Com a disseminação "através do ensino, [d]a utilização da língua portuguesa contribuindo para a consolidação da unidade nacional" (MOÇAMBIQUE, 1983, p. 15), criou-se a percepção de que o discurso de tentativa de invisibilizar a diferença cultural foi bem sucedido, o que implicou tentativas de destruição de várias exteriorizações culturais como por exemplo as línguas nativas; a tribos; as práticas culturais como casamentos tradicionais; algumas religiões, etc ${ }^{14}$. Como esse objetivo, o Governo/FRELIMO criou um sistema de controle que visava:

\begin{abstract}
Incentivar o combate ao uso da língua materna nos setores de vida e de trabalho coletivos tais como na produção, nos trabalhos manuais, na escola, no refeitório, nas reuniões, nas actividades esportivas e culturais e estimular o uso da língua portuguesa, língua de unidade nacional. Portanto não houve a diferença entre o regime colonialista e os "nacionalistas" quanto à questão das línguas e valores culturas nacionais. Ambos os encararam como empecilho contra seus interesses políticos e lutaram contra, silenciando assim a voz dos sujeitos sociais (COSSA, 2007, p. 71).
\end{abstract}

Com essa análise e discrição não estamos a militar no terreno de juízo de valores com vista a discernir o bem e o mal; os aspectos bons ou maus das tribos, das línguas nacionais etc., mas analisar as disputas pela significação de mundo/social que norteiam os discursos nacionalistas. Procuro identificar sentidos presentes nos documentos com a

\footnotetext{
${ }_{13}$ Parece que esse discurso concorda com a ideia trazida por Stuart Hall (2005, p. 49) que refere que os centros de poder querem que "a lealdade e a identificação que, numa era pré-moderna ou em sociedades mais tradicionais, eram dadas à tribo, ao povo, à religião e à região" fossem "transferidas gradualmente, nas sociedades ocidentais à cultura nacional".

14 Essa ideia é desenvolvida no pôster enviado ao Endipe 2020 intitulado "Indígenas, destribalizados e assimilados": contornos de um currículo que tenta (in)visibilizar a diferença em Moçambique" (Nhantumbo, 2020, no prelo).
} 
compreensão de que o social é uma construção mediada pela linguagem e a cultura é uma enunciação perpétua que produz sempre a diferença ${ }^{15}$.

Neste âmbito, a lei no 4/83 de 23 de Março já deixava claro essa pretensão de colocar a tribo e suas manifestações culturais fora do circuito de formação, pois o seu objetivo era de formar Homem Novo, livre de hábitos e costumes tribais, donde emergia o professor "como um educador e profissional consciente com profunda preparação científica e pedagógica, capaz de educar os jovens e adultos nos valores da sociedade socialista" (MOÇAMBIQUE, 1983, p. 15). O professor foi, neste contexto, visto como um instrumento ao serviço dos interesses nacionais. A educação tinha a tarefa de "unir todos os moçambicanos, para além das tradições e línguas diversas" o que "requer que na nossa consciência morra a tribo para que nasça a Nação" (MACHEL, 1978, p.11). Esse discurso reforça a percepção de que a unidade nacional pretendia assumir a centralidade sobre as liberdades individuais, intelectuais, religiosas etc. E que tal unidade encontrava na educação, através do subsistema de formação de professores, um instrumento de destribalizar ${ }^{16}$ e nacionalizar os moçambicanos, não só através da imposição do português como língua oficial, mas também pela proibição de manifestações de ideais tribalistas, religiosos, que na nossa óptica, poderiam enriquecer as disputas pela significação do social. Questionar se não há outras possibilidades de se pensar os projetos nacionais e educacionais fora da lógica de imposição me parecem um caminho frutífero. Bhabha nos chama a atenção para:

A necessidade de pensar além das narrativas de subjetividades originárias e iniciais e de focalizar aqueles momentos ou processos que são produzidos na articulação de diferenças culturais. Esses entrelugares fornecem terreno para a elaboração de estratégias de subjetivação - singular ou coletiva - que dão início a novos signos de identidades e postos inovadores de colaboração e contestação, no ato de definir a própria ideia de sociedade. É na emergência dos interstícios a sobreposição e deslocamento do domínio da diferença que as experiências intersubjetivas e coletivas de nação, o interesse comunitário ou o valor cultural são negociados (1998, p. 20).

Entretanto, de 1975 até 1990 - altura que é aprovada a nova constituição da República, os princípios Marxismo-Leninismo nortearam os processos de formação de

\footnotetext{
15 Essa ideia é desenvolvida no pôster enviado ao Endipe 2020 intitulado "Indígenas, destribalizados e assimilados": contornos de um currículo que tenta (in)visibilizar a diferença em Moçambique" (Nhantumbo, 2020, no prelo).

${ }^{16}$ Segundo Marcelo Caetano - último chefe do governo do Estado Novo em Portugal - citado por Curto e Cruz, (2015, p. 128) destribalizados são “[...] indivíduos que, sendo negros ou mestiços, adquiriram um verniz externo de civilização e se colocaram em rebeldia contra a disciplina tribal, repudiando as autoridades e os usos e costumes indígenas, mas sem terem assimilado concepções fundamentais da moral e da técnica do colonizador, pelo que, não sendo em rigor indígenas, também seria inexacto considerá-los não indígenas".
} 
MATAR A TRIBO PARA FAZER NASCER A NAÇÃO: A (in)visibilização da diferença na formação de professores moçambicanos

professores. Argumento que nessa fase do socialismo em Moçambique, cujos padrões culturais eram europeus, os ideais tribalistas foram igualmente combatidos, ainda que não de forma bem-sucedida. O Estado/nação assume a centralidade em todas as questões individuais. É neste contexto que "o Subsistema de Formação de Professores [...] confere ao professor a consciência de classe que o torna capaz de educar o aluno nos princípios do marxismo-leninismo" (MOÇAMBIQUE, 1983, p. 19). O currículo de formação dos professores tinha um caráter prescritivo, previamente desenhado e articulado, o que constitui um ponto de questionamento das perspectivas pós-coloniais, em que a enunciação da diferença se constitui a posteriori, e não ao contrário.

Neste âmbito, a formação de professor foi um instrumento usado pelo Estado para tentar controlar a sociedade e garantir a sua hegemonia na vida dos indivíduos. Por isso, tal subsistema visava "forjar no professor uma profunda consciência patriótica e revolucionária baseada nos princípios do partido Frelimo" 17 (MOÇAMBIQUE, 1983, p. 19). Argumento que nenhum discurso consegue fechar os sentidos em disputa. E mesmo que haja a percepção de fixação de certo sentido, ele será sempre provisório, precário e contingente, dada a instabilidade da linguagem que o medeia.

Contudo, o sistema de formação de "Homem Novo", cujos espaços de negociações eram mínimos, gerou muitas contestações no âmbito nacional, a partir de ecos vindos de círculos internacionais. No âmbito internacional, as narrativas produzidas pelo bloco socialista liderada pela então União das Repúblicas Socialista Soviética (URSS), donde partia a inspiração governativa nacionalista, são colocadas em causa, fato que culmina com a queda do muro de Berlim em 1989. Ao nível interno, a guerra civil que opunha a FRELIMO e a Resistência Nacional de Moçambique (RENAMO) - durou 16 anos (1977-1992) - (em que uma das principais reivindicações era o fim do socialismo em Moçambique; a construção de democracia multipartidária; liberdades tribais e outros tipos de liberdades; etc.), viu luz no fundo do túnel com a queda do murro de Berlim, pois foi um fator importante para que houvesse negociações de paz que aconteceu em 4 de Outubro de 1992.

Pereira e Nhantumbo (2018, p. 7) referem que a:

Estrutura política de Moçambique passou por várias reformas que culminaram na aprovação de uma nova Constituição da República em 1990. A nova Constituição abriu espaço para uma democracia multipartidária, que favoreceu a aprovação da Lei no 6 de maio de1992 do SNE. Uma Lei que rompe com os princípios marxista-leninistas e estabelece princípios educacionais mais liberais. Nesse SNE existe a

\footnotetext{
${ }^{17}$ Antes da independência nacional a FRELIMO ainda era um movimento por isso se denominava Frente de Libertação de Moçambique - FRELIMO - em maiúsculo. Contudo, depois da independência passa a ser um partido político, daí a sua designação de Frelimo escrito em minúsculo.
} 
preocupação com o resgate das línguas nacionais. O SNE passa a "valorizar e desenvolver as línguas nacionais, promovendo a sua introdução progressiva na educação dos cidadãos" (Moçambique, 1992, p. 8). No sentido de reforçar o SNE, em 1995 foi aprovada a Política Nacional da Educação (PNE) (através da Resolução n ${ }^{\circ} .8$ de 22 de agosto de 1995) que dentre vários princípios estabelece a "definição e aplicação das modalidades da introdução das línguas maternas como línguas de ensino das classes iniciais do EP1 ( $1^{\mathrm{a}}$ e $2^{\mathrm{a}}$ classes)" (MOÇAMBIQUE, 1995, p. 179).

Entretanto, a ideia de introdução progressiva das línguas nativas no SNE ainda está numa fase de avaliação das experiências iniciadas de 1993 a 1997 nas províncias de Gaza e Tete. Hoje, 27 anos depois da introdução piloto do ensino/educação bilíngue ${ }^{18}$ no ensino fundamental, ainda continua num "estágio piloto", num contexto em que até 2019, apenas 3,6 milhões de habitantes falam o português num total de 28,8 milhões de moçambicanos. O que demonstra a importância do uso das línguas nativas no subsistema formação de professores. Por dificuldades de vária ordem, desde fatores político (a maioria das línguas nativas está associada a uma tribo, o que pode, em minha opinião, colocar a ideia de nação em causa); fatores profissionais ligados ao enquadramento dos professores formados numa dada região de acordo com a língua nativa que domina para facilitar a enunciação da aula; etc., a educação bilíngue aguarda a sua massificação pelo resto do país.

Com a aprovação da nova lei do SNE de 1992 não houve muitas mudanças, apenas abriu-se espaços para que as políticas neoliberais atuassem não como ideologia de cunho socialista, mas nacionalista marcada pela ideia de construção da nação. Foi através desta lei que o Estado deixa de ser o único provedor da educação e abre espaços para iniciativas privadas e religiosas, a fim de poder dar conta de tanta demanda por uma formação formal. A abertura do mercado ou a inscrição do país no modelo neoliberal através de aderência às políticas de Bretton Woods a partir de 1984 (em que as iniciativas privadas ganham relevos face ao Estado) trouxe pressão para o processo de formação de professores primário-básicos. Se no período anterior a pressão vinha da demanda dos alunos por formação formal, onde apenas o Estado detinha o monopólio de educar, nessa nova fase, as novas instituições de ensino privado se ressentem da escassez de professores para servirem seus interesses. Essas novas pressões exigem do Estado medidas e modelos de formação de professores às vezes de curta duração, e outras de longa duração, como narram Agibo e Chicote (2015, p. 5), ao se referirem que:

\footnotetext{
${ }^{18}$ No contexto do SNE, entende-se por educação bilíngue "o uso de duas ou mais línguas como meio de ensino. No caso da Republica de Moçambique a educação bilíngue consiste no uso de uma língua moçambicana de origem bantu ou línguas de sinais de Moçambique, língua materna do aluno (L1) e da língua oficial, o português, que, de uma forma geral, constitui a sua língua segunda (L2)" (MOÇAMBIQUE, 2018, p. 24).
} 
MATAR A TRIBO PARA FAZER NASCER A NAÇÃO: A (in)visibilização da diferença na formação de professores moçambicanos

Desde a sua independência, em 1975, Moçambique tem experimentado vários modelos de formação de professores, destacando alguns: $6^{\mathbf{a}}$ classe + um a três meses que vigorou de 1975 a $1977,6^{\mathrm{a}}$ classe + seis meses, de 1977 a 1982, $6^{\text {a }}$ classe +1 ano, 1982 e 1983, $6^{\text {a }}$ classe +3 anos, de 1983 a 1991, $7^{\text {a }}$ classe +3 anos, de 1991 aos nossos dias, IMAP $\left(10^{\mathrm{a}}\right.$ classe +2 anos $)$, de 1997 aos nossos dias, $7^{\mathrm{a}}$ classe +2 anos +1 ano, em regime experimental, de 1999 à 2003, IMAP $\left(10^{\text {a }}\right.$ classe +1 ano +1 ano), de 1999 a 2004 e atualmente $10^{\text {a }}$ classe +3 anos, que está sendo implementado em alguns Institutos do País. Em fevereiro de 2004, foi feita a transformação curricular para o ensino básico, com objetivo de dar vazão a crescente demanda pela educação primária em Moçambique. Nesta direção, o governo, instigado a responder cabalmente a constante demanda pela educação, concebeu e pós em vigor em 2008, o modelo de formação $10^{\mathrm{a}}+1$ ano.

A formação dos professores primários tem se processado a um rimo abaixo da demanda, daí que o rácio professor-aluno tem sido assustador. Se nos primeiros anos da independência existiam turmas em que um professor estava para 85 alunos (GASPERINE, 1989, p. 50), atualmente, apesar do esforço, ainda há registro de um docente estar para 65 alunos. Ainda há escolas que também enfrentam problemas de ordem infraestrutural, em que o professor tem que dar aulas debaixo de uma árvore e ao ar livre. Nessas condições os alunos se assentam ao chão, sem meios para apoiar os cadernos de anotação, o que dificulta, por exemplo, o exercício de escrita. Este cenário reforça a ideia de que o currículo como enunciação ressignifica o contexto escolar, criando várias possibilidades de o professor negociar sempre com o contexto, muitas vezes tão adverso e inesperado.

Num contexto em que as políticas da Bretton Woods, que assume uma perspectiva econômica neoliberal têm impactado negativamente os investimentos públicos também na área de educação, vemos reforçado a vulnerabilidade do sistema educativo e, isso simboliza a ressignificação persistente das relações de dependência que marcam a história do País.

Contudo, em 2018 foi aprovado o terceiro modelo de SNE - através da Lei $\mathrm{n}^{\circ}$ 18/2018 de 28 de Dezembro - em que não houve muitas inovações senão o alargamento de ensino obrigatório de $1^{\mathrm{a}}$ a $7^{\mathrm{a}}$ classe para $1^{\mathrm{a}}$ a $9^{\mathrm{a}}$ classe. Esse alargamento traz desafios aos processos de formação de professores, na medida em que os mesmos devem se adaptar ao novo contexto curricular, em que "assegurar a todo o cidadão o acesso à educação e à formação profissional” (MOÇAMBIQUE, 2018, p. 20), se configura como uma meta. 
Entretanto, mesmo com essa nova reforma educacional, as línguas nacionais nos processos de formação de professores continuam na sua posição secundária, o que produz em mim o entendimento de que as mesmas são vistas pelos nacionalistas/governo como utensílios históricos ultra-abstratos, o que contrasta com a ideia de vê-las como "práticas sociais historicamente situadas" (NHAMPOCA, 2015, p. 87) apud (SEVERO, 2014, p. 11) e discursivamente construídas ${ }^{19}$ e, por isso, em perpétuo processo de ressignificação. Assim, o SNE de 2018 produz um discurso visando:

j)Valorizar as línguas, cultura e história moçambicana com o objectivo de preservar e desenvolver o património cultural da nação; k) desenvolver as línguas nacionais e as línguas de sinais, promovendo a sua introdução progressiva na educação de cidadãos, visando a sua transformação em língua de acesso ao conhecimento científico e técnico, à informação bem como de participação aos processos de desenvolvimento do País; 1) desenvolver o conhecimento da língua portuguesa como língua oficial e meio de acesso ao conhecimento científico e técnico, bem como de comunicação entre moçambicanos com o mundo (MOÇAMBIQUE, 2018, p. 20).

\section{Considerações finais}

Entender o processo de formação de professores em Moçambique num contexto de controle e resistência permite pensar que mesmo em situações adversas ocorrem negociações. Os processos enunciativos presentes em tudo que é social produzem ambivalências, a partir da qual, questões tidas como sedimentadas são contestadas. Os discursos articulados na ideia de matar a tribo para fazer nascer à nação, ainda que ressignificadas em cada momento, só se mantem em pé devido a uma repetição constante: como narração.

Ao analisarmos os três momentos do SNE não significou que havia marcas de uma origem ou fundamentos/essências, mas nos permitiu pensar os discursos circunscritos nesses espaços-tempos. Consideramos o currículo de formação de professores como algo que não tem rastro, mas que emerge aqui e agora, "no de repente", dentro do espírito híbrido. Os ideais nacionalistas prescritivos e homogêneos serviram como pontos de questionamento para argumentar que a formação de professores envolve o descarte de uma perspectiva de identidade, em favor da diferença. Em um contexto (sempre a posteriori) em que a única certeza que temos é a incerteza, pois a enunciação

\footnotetext{
${ }^{19}$ Essa ideia é desenvolvida no pôster enviado ao Endipe 2020 intitulado "Indígenas, destribalizados e assimilados": contornos de um currículo que tenta (in)visibilizar a diferença em Moçambique" (NHANTUMBO, 2020, no prelo).
} 
MATAR A TRIBO PARA FAZER NASCER A NAÇÃO: A (in)visibilização da diferença na formação de professores moçambicanos

ressignifica/muda o acontecimento ou o modo como se (re)lê os documentos/o social da lógica de repetição para iteração ${ }^{20}$.

\section{Referências bibliográficas}

AGIBO, Júlio Miguel; LACOTE, Maria Luísa L. Modelos de formação de professores em Moçambique: uma análise no processo histórico. In: VIII encontro de pesquisa em educação. III congresso internacional trabalho docente e processos educativos. Uberaba, Minas Gerais, UNIUBE, 2015. 22/22 set. p. 1-10. Disponível em: https://www.uniube.br/ eventos/epeduc/2015/completos/64.pdf acesso em 22/02/2020

ALMEIDA, Rosely dos Santos; CUNHA, Érika Virgílio R. da. Campos e experiências na Base Nacional Comum Curricular (BNCC): evocando o conhecimento a ser ofertado na educação infantil. In: LOPES, A. C.; OLIVEIRA, Marcia B (org.). Políticas de currículo: pesquisas e articulações discursivas. Curitiba: CRV, 2017. p. 149-167.

BHABHA, K. Homi. O bazar global e o clube dos cavalheiros ingleses. Rio de Janeiro: Rocco Digital, 2012.

BHABHA, H. O local da Cultura. Belo Horizonte: Editora UFMG, 2019.

BHABHA, H. O local da Cultura. Belo Horizonte: Editora UFMG, 2007.

BHABHA, H. O local da Cultura. Belo Horizonte: Editora UFMG, 1998.

CABAÇO, J. L. de O. Moçambique: Identidades, colonialismo e libertação. 2007. Tese (Doutorado em Antropologia) - Universidade de São Paulo, São Paulo, 2007.

COSSA, Lourenço Eugénio Línguas Nacionais no Sistema de Ensino para o Desenvolvimento da Educação em Moçambique. Dissertação (Mestrado em Educação) Porto Alegre: UFRGS, 2007.

CURTO, Diogo Ramada; CRUZ, Bernardo Pinto da. Destribalização, regedorias e desenvolvimento comunitário: notas acerca do pensamento colonial português (19101965). In: Práticas da História, Journal on Theory, Historiography and Uses of the Past 1, 2015, n. ${ }^{\circ}$ 1, p. 113-172. Disponível [online] em: http://www.praticasdahistoria.pt/ issues/2015/11/PDH_01_RamadaCurto_PintoCruz.pdf. Acesso 09/12/2019

FERREIRA, Marcia Serra; SANTOS, André dos. Discursos curriculares no/do tempo presente: subsídios para uma articulação entre a história e as políticas do currículo. p. 57-

\footnotetext{
20 A iteração como acontecimento ou memória "não remete à criação de nexo causal que repete o passado e torna o presente desconexo, mas como significante, rompe com uma linearidade temporal e espacial ao desestabilizar a imagem sequencial e homogénea da história" (RAMOS; FRANGELLA, 2014, p. 239).
} 
79. In: LOPES, A. C.; OLIVEIRA, Marcia B (org.). Políticas de currículo: pesquisas e articulações discursivas. Curitiba: CRV, 2017

FRANCISCO, António. Sociedade civil em Moçambique: expectativas e desafios. In IESE. Sociedade civil em Moçambique: desafios para Moçambique. Maputo: IESE, 2010 Disponível [online] em: http://www.iese.ac.mz/lib/publication/livros/des2010/IESE Des2010_3.SocCivil.pdf acesso 21/05/2019.

GASPERINI, Lavinia. Moçambique: educação e desenvolvimento rural. Roma: Edizioni Lavoro, 1989.

GONÇALVES, António C. Parafino. Educação politécnica e a escola de trabalho em Moçambique: Novas e velhas falácias pedagógicas? Maputo, Edição CEC: 2015. 188 p.

HALL, S. Quem precisa da identidade? In: SILVA, T. T. da (Org.). Identidade e diferença: a perspectiva dos estudos culturais. Petrópolis: Vozes, 2000, p. 103-133

The centrality of culture: notes on the cultural revolutions of our time. In:

THOMPSON, Kenneth (ed.). Media and cultural regulation. London, Thousand Oaks, New Delhi: The Open University; SAGE Publications, 1997. (Cap. 5).

JACOBS, Monica. O currículo. In: LEMMER, Eleanor (org.). Educação contemporânea: questões e tendências globais. 1. ed., Maputo: Texto editores, 2006.

LIMA, Paula Sophia Branco de. Moçambique como lugar de interrogação: a modernidade em Elísio Macamo e Severino Ngoenha. Cape Town: AFRICAN MINDS, 2016.

LOPES, Alice C.; OLIVEIRA, Marcia B. Redes de pesquisa e articulações discursivas nas políticas de currículo. p. 11-29. In: LOPES, A. C.; OLIVEIRA, Marcia B (org.). Políticas de currículo: pesquisas e articulações discursivas. Curitiba: CRV, 2017

LOPES, Alice C.; MACEDO, E. Teoria de Currículo. São Paulo, Cortez Editora: 2011.

MACEDO, Elizabeth. Mas a escola não tem que ensinar? Conhecimento, reconhecimento e alteridade na teoria do currículo. Currículo sem Fronteiras, v. 17, n. 3, p. 539-554, set./dez. 2017.

. Base nacional curricular comum: a falsa oposição entre conhecimento para fazer algo e conhecimento em si. Educação em Revista. Belo Horizonte, v. 32, n. 02, p. 45-67, abr/jun., 2016. Disponível em: < http://www.scielo.br/scielo.php?pid=S0102-

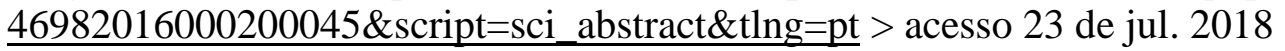

Base nacional comum para currículos: direito de aprendizagem e desenvolvimento para quem? Educação e Sociedade, Campinas, v. 36, n. 133, p. 891908, out.-dez., 2015. 
MATAR A TRIBO PARA FAZER NASCER A NAÇÃO: A (in)visibilização da diferença na formação de professores moçambicanos

Que queremos dizer com educação para a cidadania? pp. 89-114. In LOPES, Alice C.; LOPES; LEITE, Carlinda; (Org.): Políticas educativas e dinâmicas curriculares no Brasil e em Portugal. Porto: Livpsic, 2008.

Currículo como espaço-tempo de fronteira cultural. Revista Brasileira de Educação. V. 11, n. 32, p. 285-296, maio/ago. 2006a.

Currículo e hibridismo: para politizar o currículo como cultura. Educação em Foco-Questões Contemporâneas de Currículo, v. 8, n. 1 e 2, p. 13-30, mar/ago. 2003, set/fev 2003/2004.

MACHEL, Samora. M. Mozambique: Sowing the Seeds of Revolution. London: CFMAG, 1974.

MAZULA, B. Educação, Cultura e Ideologia em Moçambique: 1975-1985. Maputo: Ed. Afrontamento: 1995.

MOÇAMBIQUE. República de. Sistema Nacional de Educação. Maputo: Conselho de Ministros, 2018.

1995.

República de. Política Nacional da Educação. Maputo: Conselho de Ministros,

República de. Sistema Nacional de Educação. Maputo: Assembleia da República, 1992.

República Popular de. Projeto da Lei do Sistema Nacional de Educação - Lei $n^{o}$ 4/83 de 23 de Março. Maputo: Assembleia Popular, 1983.

NGOENHA, S. E. Estatuto e Axiologia de Educação em Moçambique: o paradigmático questionamento da Missão Suíça. Maputo: Livraria Universitária, 2000.

NGUNGA, Armindo. Os desafios da investigação linguística em África: o caso de Moçambique. In: A Pesquisa na Universidade Africana no Contexto da Globalização: Perspetivas Epistemológicas Emergentes, Novos Horizontes Temáticos, Desafios. São Paulo: CEA-USP, 2012.

NHANTUMBO, Hermínio E. Educação pós-colonial em Moçambique: tentativas de inclusão num currículo culturalmente excludente. In: Trabalhos Completos do XI Seminário Regional da ANPAE Sudeste/ XI Encontro Regional SUDESTE da ANFOPE/ XIV: Encontro Estadual da ANFOPE-RJ / VII Seminário Estadual da ANPAE-RJ. Rio de Janeiro, RJ, 2018. p. 186-197. Disponível em http://www.anfope.org.br/wpcontent/uploads/2019/01/1548878967632_ANAIS-TRABALHOS-COMPLETOS-doXI-Encontro-Reg-SUDESTE-ANFOPE-e-XI-Seminario-Reg-SUDESTE-ANPAEAgosto2018.pdf Acesso em 23/02/2019 
, "Indigenas, destribalizados e assimilados": contornos de um currículo que tenta (in)visibilizar a diferença em Moçambique" (Nhantumbo, 2020, no prelo). Endipe 2020, Rio de Janeiro. No prelo

OLIVEIRA, Mayre-Ester B. de; FRANGELLA, Rita de Cassia P. Conectando currículo, política e cultura numa perspectiva discursiva. pp 81-95. In: LOPES, A. C.; OLIVEIRA, Marcia B. (org.). Políticas de currículo: pesquisas e articulações discursivas. Curitiba: CRV, 2017.

OLIVEIRA, Cristiane G. de; CAMÕES, Maria C. S.; FRANGELLA, Rita de C. P. "Essa escola só serve para adultos mandarem nas crianças": Alteridade, infância e formação. In: MACEDO, Elizabeth; MENEZES, Isabel (Org.). Currículo, política e cultura: conversas entre Brasil e Portugal. Curitiba: CRV, 2019

RAMOS, Aura H.; FRANGELLA, Rita de Cássias P. Currículo, cultura e formação: desafios para a universidade frente às directrizes nacionais para a educação em direitos humanos. pp. 229-251. In: LOPES, Alice C; ALBA, Alicia de. (Org.). Diálogos curriculares entre Brasil e México. Rio de Janeiro: EdUERJ, 2014. 340p.

PEREIRA, Talita Vidal; NHANTUMBO, Hermínio Ernesto, When the Nation Kills the Tribe: The paradox of a School Curriculum Suitable for All. Transnational Curriculum Inquiry 15 (1) http://nitinat.library.ubc.ca/ojs/index.php/tci acess date $7^{\text {th }} / 11 / 2018$

SCHIMIDT, Rita Terezinha. O pensamento-compromisso de Homi Bhabha: notas para uma introdução, p.13-61. In: BHABHA, Homi K. Bazar Global e o clube dos cavaleiros ingleses. Rio de Janeiro, Rocco, 2011.

SILVA, Tomaz T. da. A produção social da identidade e da diferença. In: SILVA, Tomaz Tadeu (org. e trad.). Identidade e diferença: a perspectiva dos estudos culturais. Petrópolis: Vozes, 2000. p. 73-102.

THIONG'O, N. W. Decolonizing the Mind: The politics of language in African literature. London: Heinemann, 1986.

ZIMBICO, O. J. Morre a Tribo e nasce a Nação? Política, Administração e História do Ensino Primário em Moçambique. 2016. Tese (Doutorado em Educação) - Faculdade de Educação, Rio de Janeiro: Universidade do Estado do Rio de Janeiro, 2016. 409f.

Recebido em: 21 mar. 2020.

Aprovado em: 20 mai. 2020. 
MATAR A TRIBO PARA FAZER NASCER A NAÇÃO: A (in)visibilização da diferença na formação de professores moçambicanos

* Hermínio Ernesto Nhantumbo é doutorando no Programa de Pós-Graduação em Educação da Universidade do Estado do Rio de Janeiro (PROPEd-UERJ), bolsista do PEC/CNPq e membro do Grupo de Pesquisa: Currículo - sujeito, conhecimento e cultura (UERJ). É licenciado em Filosofia e Mestre em Educação pela Universidade de Moçambique.

E-mail: herminionhantumbo@gmail.com

http://orcid.org/0000-0002-3923-4045 